\title{
Dysregulation in growth arrest-specific 5 and metastasis-associated lung adenocarcinoma transcript 1 gene expression predicts diagnosis and renal fibrosis in systemic lupus erythematosus patients
}

Manal M. El-Desoky ${ }^{1 *} \mathbb{D}$, Rasha S. Shemies ${ }^{2}$, Amany S. El-Bahnasawy ${ }^{3}$, Nora Mostafa ${ }^{1}$ and Mona Elhelaly ${ }^{1}$

\begin{abstract}
Background: Biomarkers that enhance overall diagnosis and prognosis of systemic lupus erythematosus (SLE) have a growing need to be recognized. The use of long non-coding ribonucleic acids (IncRNAs) as biomarkers in this regard is still largely unexplored. This study aimed to evaluate IncRNA [metastasis-associated lung adenocarcinoma transcript 1 (MALAT1) and growth arrest-specific 5 (GAS5)] expression in SLE patients with/without nephritis. Their relation to disease activity/chronicity changes has been identified. A total of 40 SLE patients and 40 healthy controls were tested using real-time quantitative polymerase chain reaction (PCR) for expression levels of MALAT1 and GAS5.

Results: MALAT1 expression was aberrantly upregulated, while GAS5 was downregulated in patients with SLE versus controls. GAS5 relative expression was significantly downregulated in lupus nephritis (LN) patients compared to non-lupus nephritis (NN) patients. GAS5 was also correlated with glomerulosclerosis, interstitial fibrosis, tubular atrophy, and hypertension.

Conclusion: The IncRNA (GAS5 and MALAT1) may serve as diagnostic biomarkers for SLE. Moreover, GAS5 may distinguish SLE LN patients from NN patients and may predict renal fibrosis in LN patients.

Keywords: Growth arrest-specific 5, Long non-coding RNA, Metastasis-associated lung adenocarcinoma transcript 1,
\end{abstract} Systemic lupus erythematosus

\section{Background}

SLE is a complex autoimmune disease defined by the existence of autoantibodies, which are reactive antibodies produced by the immune system to recognize one or more of individual proteins, deposition of immune

\footnotetext{
* Correspondence: drmanal@live.com

${ }^{1}$ Medical Biochemistry Department, Faculty of Medicine, Mansoura University, Mansoura, Egypt

Full list of author information is available at the end of the article
}

complex, and excess proinflammatory cytokine. This causes serious damage to various organ systems [1]. Biomarkers facilitate diagnosis and prognosis [2] because of the heterogeneous presentation and unpredictable course of SLE patients. The use of IncRNAs as biomarkers in this regard is still mostly unexplored [3]. LncRNAs is a class of endogenous cellular RNAs with lengths greater than 200 nucleotides, and they are not translated into proteins. They lie within protein-coding

\section{Springer Open}

( ) The Author(s). 2021 Open Access This article is licensed under a Creative Commons Attribution 4.0 International License, which permits use, sharing, adaptation, distribution and reproduction in any medium or format, as long as you give appropriate credit to the original author(s) and the source, provide a link to the Creative Commons licence, and indicate if changes were made. The images or other third party material in this article are included in the article's Creative Commons licence, unless indicated otherwise in a credit line to the material. If material is not included in the article's Creative Commons licence and your intended use is not permitted by statutory regulation or exceeds the permitted use, you will need to obtain permission directly from the copyright holder. To view a copy of this licence, visit http://creativecommons.org/licenses/by/4.0/. 
gene intergenic stretches or overlap antisense transcripts [2]. They are quite numerous and involved in almost all aspects of cell biology such as cell differentiation, cell proliferation, and response to DNA damage [4].

They also play a defined role in numerous multigenetic human diseases such as cancer and neurological diseases. They currently attract many researchers to their role in autoimmune disorders including rheumatoid arthritis and SLE [5].

MALAT1, also known as nuclear-enriched abundant transcript 2 (NEAT2) or alpha, is a highly conserved lncRNA [6]. This gene was first identified in 2003. It was found in early-stage non-small cell lung cancer (NSCLC) cells with high expression levels [7]. It is highly regulated in various cancer forms: endometrial cancer, breast cancer, cervical cancer, colorectal cancer, and hepatocellular carcinoma [8]. Moreover, even normal physiological processes of cells are associated with MALAT1 [9]. GAS5 is a lncRNA, which competes with glucocorticoid response elements (GREs). Since glucocorticoids are powerful immunosuppressants, increased expression of lncRNAGAS5 in immune cells can suppress glucocorticoid action and can make a significant contribution to autoimmune diseases [10]. Although the precise pathophysiology of SLE remains unknown, its multifactorial etiology is well-known, involving mainly genetic, epigenetic, and environmental factors $[1,11]$. Recent studies emphasize the role of lncRNAs and low protein-coding potential in SLE pathogenesis [12, 13]. However, these studies are few, and further studies shall be conducted to support diagnostic and prognostic utility in SLE.

The present study aimed to evaluate the expression of long non-coding RNA gene (MALAT1 and GAS5) in SLE patients with/without nephritis and study their relation to disease activity and chronicity changes.

\section{Methods}

The study includes 40 SLE-LN/NN patients enlisted in the author's hospital outpatient clinics and 40 agematched and sex-matched in healthy controls between October 2017 and October 2019. A written consent is obtained from all individuals concerned with this study, and it is approved by the Institutional Ethics Committee (IEC).

All SLE patients have met the SLE classification requirements of the American College of Rheumatology (ACR) $[14,15]$. Both clinical examination and laboratory investigations were done. The Score of Systemic Lupus Erythematosus Disease Activity Index (SLED AI) for each patient is determined during blood withdrawal [2]. Depending on the SLEDAI results, patients were divided into patients with active disease (scores $>4$ ) or patients with inactive disease (scores < 4) [16]. SLE renal involvement was defined according to
ACR criteria, depending on nephritis presence/absence. All LN patients have undergone a kidney biopsy. The study excluded concurrent infection patients. Healthy controls did not have any autoimmune diseases or treatment by immunosuppressive agents.

Five millimeters of blood was collected from each subject in ethylenediaminetetraacetic acid (EDTA) collection tubes. Peripheral mononuclear blood cell (PBMC) isolation was done using Histopaque-1077 (Sigma-Aldrich) Ficoll density-gradient centrifugation according to the manufacturer instructions.

Total RNA, including lncRNA, was extracted by the TRIzol reagent from PBMCs (Zymo Research, Irvine, CA). NanoDrop 2000 (Thermo Fischer Scientific, Waltham, MA) was used to determine the concentrations of RNA. The reversed transcript on the RNA was performed using SensiFAST cDNA Synthesis Kit [Bioline, Memphis, TN] with a $20 \mathrm{ml}$ final reaction volume. The expression levels of MALAT1 and GAS5 lncRNAs were evaluated according to the internal control, glyceraldehyde 3-phosphate dehydrogenase (GAPDH), using a Hera Plus SYBR Green qPCR Kit (Willow Fort, Birmingham, UK) according to the manufacturer's protocol.

Fold change was calculated using the comparative threshold cycle $\left[2^{-\Delta \Delta \mathrm{Ct}}\right]$ for relative quantification which is normalized to an endogenous control [17]. The PCR primer sequences were as follows: MALAT1 forward primer, GAATTGCGTCATTTAAAGCCTAGTT and reverse primer, GTTTCATCCTACCACTCCCAATTA AT; GAS5 forward primer, CTTCTGGGCTCAAGTG ATCCT and reverse primer, TTGTGCCATGAGACTC CATCAG; GAPDH forward primer, ACAGTCAGCC GCATCTTCTT and reverse primer, GACAAGCTTC CCGTTCTCAG. Real-time PCR was performed using 7500 Real-Time PCR Systems [Applied Biosystems] under the following conditions: $95^{\circ} \mathrm{C}$ for $10 \mathrm{~min}$, followed by 40 cycles at $95^{\circ} \mathrm{C}$ for $15 \mathrm{~s}$ and $60^{\circ} \mathrm{C}$ for $60 \mathrm{~s}$.

\section{Statistical analysis}

Social Science Software Computer Program version 26 [SPSS, Inc., Chicago, IL, USA] was used to analyze obtained data. Non-parametric data were presented by the median and interquartile range, while means and standard deviation were used for parametric data. Student's $t$ test was used to compare quantitative parametric data, while Mann-Whitney $U$ test was used for quantitative non-parametric data. On the other hand, Kruskal-Wallis $H$ test was followed by Dunn's post hoc test for pairwise comparison. Pearson's chi-square or Fisher exact test was used to compare qualitative data, and Spearman correlation was used to correlate different parameters. The receiver operating characteristic (ROC) curve was 
Table 1 Comparison of GAS5 and MALAT1 relative expression in all studied groups

\begin{tabular}{|c|c|c|c|c|}
\hline Variable & All cases & & Control & $p$ value \\
\hline Relative expression of GAS5 & $0.52(0.19-1.02)$ & & $0.98(0.88-1.06)$ & $0.001^{*}$ \\
\hline \multirow[t]{2}{*}{ Relative expression of MALAT1 } & $3.13(1.69-5.15)$ & & $0.91(0.84-1.17)$ & $<0.001^{*}$ \\
\hline & Non-nephritis & Nephritis & Control & \\
\hline Relative expression of GAS5 & $0.91(0.42-1.28)$ & $0.24(0.17-0.67)^{a}$ & $0.98(0.88-1.06)^{b}$ & $<0.001^{*}$ \\
\hline Relative expression of MALAT1 & $3.58(1.50-5.63)$ & $2.60(1.89-4.20)$ & $0.91(0.84-1.17)^{a b}$ & $<0.001^{*}$ \\
\hline
\end{tabular}

Data are expressed as median (IQR). Tests used: Mann-Whitney $U$ test and Kruskal-Wallis followed by Dunn's post hoc for data expressed as median (IQR) $p p$ value

*Significance $<0.05$

${ }^{a}$ Significance vs non-nephritis

${ }^{b}$ Significance vs nephritis

also used to determine the diagnostic power of each test. The statistically relevant $p$ value $<0.05$ was regarded.

\section{Results}

The expression levels of lncRNAs (MALAT1 and GAS5) in PBMCs taken from 40 patients with SLE and 40 healthy controls were measured using RTqPCR.

MALAT1 mRNA transcripts were higher in SLE patients compared to controls $(p<0.001)$ (Table 1, Fig. 1a). There were also significant differences between LN and NN patients compared to controls $(p=<0.001)$
(Table 1, Fig. 1c). However, there were no statistically significant differences with respect to MALAT1 in LN patients relative to NN patients $(p=0.25)$ (Table 2).

The expression of GAS5 was significantly lower in SLE patients as compared to controls $(p<0.001)$ (Table 1 , Fig. 1b). Also, the expression of GAS5 was decreased significantly in patients with LN compared with healthy donors and patients with $\mathrm{NN}(p<0.001$ and $p=0.003$, respectively) (Tables 1 and 2, Fig. 1d).

SLE subgroups showed a significant difference in clinical/laboratory characteristics including blood pressure $(p=0.007)$, urinary output (UOP) $(p<0.001)$,
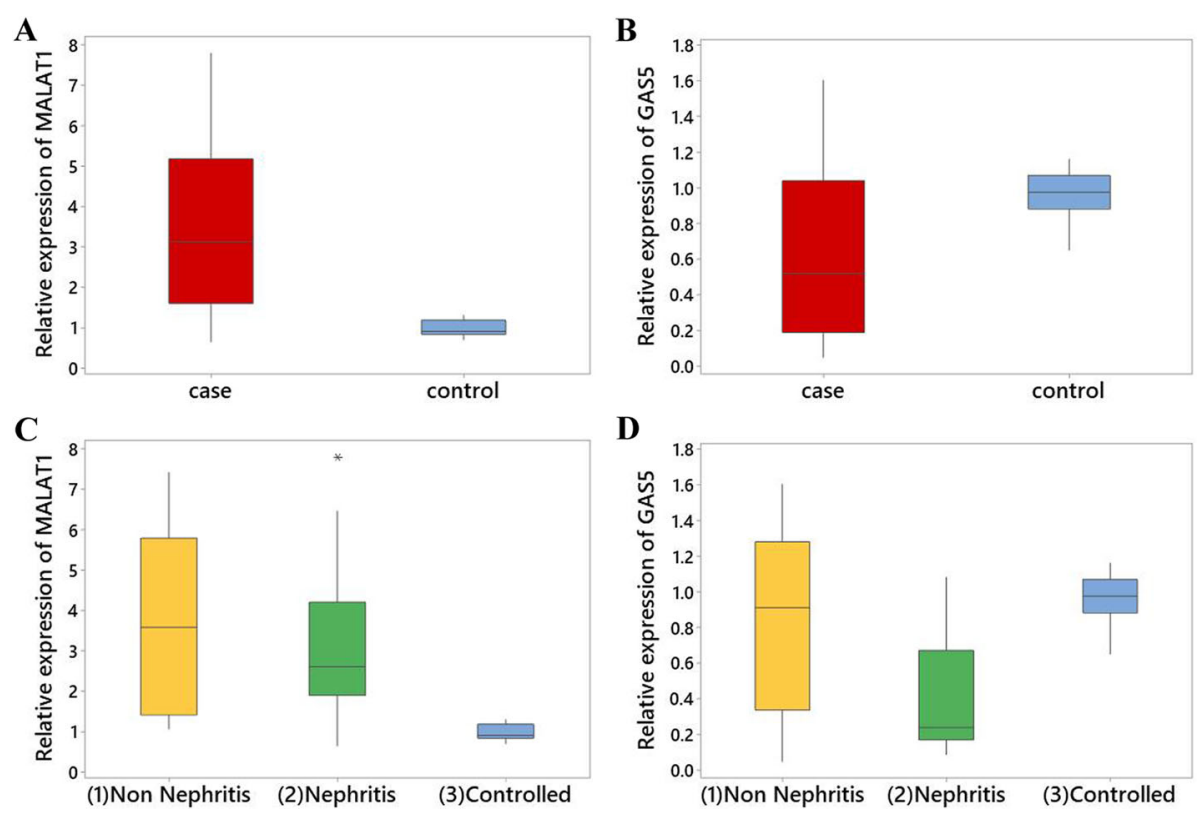

Fig. 1 The relative expression of GAS5 and MALAT1 between SLE patients and controls a MALAT1 relative expression between SLE groups versus controls. MALAT1 expression is significantly higher in SLE patients compared to control group $(p=<0.001)$. b GAS5 relative expression between SLE groups versus controls. GAS5 expression was significantly lower than the control group $(p=<0.001)$. c MALAT1 relative expression between two SLE subgroups, nephritis, and non-nephritis versus controls showed a significant difference in LN and NN patients compared to control cases $(p=<0.001)$. However, there were no statistically significant differences in LN patients compared to NN $(p=0.25)$. $\mathbf{d}$ GAS5 relative expression between the two SLE subgroups, nephritis, and non-nephritis versus controls showed a significant difference in LN patients compared to control groups $(p=<0.001)$. In addition, GAS5 showed significant downregulation in LN patients compared to NN patients $(p=0.003)$. Red, SLE cases; blue, control group; yellow, NN; green, LN; $p, p$ value. The central box in the diagram represents the lower and upper quartiles (IQR). The central horizontal line in the box represents the median 
Table 2 Clinical and laboratory characteristics of the study patients

\begin{tabular}{|c|c|c|c|c|c|c|c|c|}
\hline \multicolumn{2}{|l|}{ Variables } & \multicolumn{2}{|c|}{ Non nephritis } & \multicolumn{2}{|c|}{ Nephritis } & \multicolumn{2}{|c|}{ Total } & \multirow{2}{*}{$\begin{array}{l}p \\
0.007^{*}\end{array}$} \\
\hline Blood pressure & Average & 18 & $85.7 \%$ & 8 & $42.1 \%$ & 26 & $65.0 \%$ & \\
\hline & Hypotensive & 0 & $0.0 \%$ & 0 & $0.0 \%$ & 0 & $0.0 \%$ & \\
\hline & Hypertensive & 3 & $14.3 \%$ & 11 & $57.9 \%$ & 14 & $35.0 \%$ & \\
\hline \multirow[t]{4}{*}{ UOP } & Average & 14 & $66.7 \%$ & 5 & $26.3 \%$ & 19 & $47.5 \%$ & $<0.001^{*}$ \\
\hline & Anuria & 1 & $4.8 \%$ & 2 & $10.5 \%$ & 3 & $7.5 \%$ & \\
\hline & Oliguria & 6 & $28.6 \%$ & 11 & $57.9 \%$ & 17 & $42.5 \%$ & \\
\hline & Polyuria & 0 & $0.0 \%$ & 1 & $5.3 \%$ & 1 & $2.5 \%$ & \\
\hline \multirow[t]{2}{*}{ Proteinuria } & No & 20 & $95.2 \%$ & 0 & $0.0 \%$ & 20 & $50.0 \%$ & $<0.001 *$ \\
\hline & Yes & 1 & $4.8 \%$ & 19 & $100.0 \%$ & 20 & $50.0 \%$ & \\
\hline \multirow[t]{5}{*}{ Casts in urine } & None & 19 & $90.5 \%$ & 8 & $42.1 \%$ & 27 & $67.5 \%$ & $<0.001^{*}$ \\
\hline & Granular & 1 & $4.8 \%$ & 4 & $21.1 \%$ & 5 & $12.5 \%$ & \\
\hline & Hyaline & 0 & $0.0 \%$ & 1 & $5.3 \%$ & 1 & $2.5 \%$ & \\
\hline & Mixed "Granular\&Hyaline" & 1 & $4.8 \%$ & 5 & $26.3 \%$ & 6 & $15.0 \%$ & \\
\hline & Crystal & 0 & $0.0 \%$ & 1 & $5.3 \%$ & 1 & $2.5 \%$ & \\
\hline \multicolumn{2}{|c|}{ Relative expression of GAS5 (Median [IQR]) } & \multicolumn{2}{|c|}{$0.91[0.42-1.28]$} & \multicolumn{2}{|c|}{$0.24[0.17-0.67]$} & \multicolumn{2}{|c|}{$0.52[0.19-1.02]$} & $0.003^{*}$ \\
\hline \multicolumn{2}{|c|}{ Relative expression of MALAT1 (median [IQR]) } & \multicolumn{2}{|c|}{$3.58[1.50-5.63]$} & \multicolumn{2}{|c|}{2.60 [1.89-4.20] } & \multicolumn{2}{|c|}{$3.13[1.69-5.15]$} & 0.25 \\
\hline \multicolumn{2}{|l|}{$\mathrm{Hb}($ mean $\pm \mathrm{SD})$} & \multicolumn{2}{|c|}{$9.3 \pm 1.9$} & \multicolumn{2}{|c|}{$8.8 \pm 2.0$} & \multicolumn{2}{|c|}{$9.1 \pm 1.9$} & 0.38 \\
\hline \multicolumn{2}{|c|}{$\mathrm{RBC}($ mean $\pm \mathrm{SD})$} & \multicolumn{2}{|c|}{$3,761,905 \pm 763,869$} & \multicolumn{2}{|c|}{$3,584,211 \pm 977,993$} & \multicolumn{2}{|c|}{$3,677,500 \pm 865,305$} & 0.52 \\
\hline \multicolumn{2}{|c|}{ WBC (median [IQR]) } & 5600 & 9800] & 6790 & $-15,000]$ & 6500 & $\cdot 13,850]$ & 0.27 \\
\hline Lymphocytes (n & edian [IQR]) & 130 & 700] & 1400 & $-1800]$ & 1400 & 800] & 0.66 \\
\hline PLT (median [IQ & & 210 & $5,000-295,000]$ & 162, & 7000-218,000] & 203 & $3,000-267,500]$ & 0.15 \\
\hline S. creatinine ( $\mathrm{m}$ & dian [IQR]) & 0.9 & & 1.5[ & & 0.9[ & & $0.004^{*}$ \\
\hline $\mathrm{cNa}$ (mean $\pm \mathrm{S}$ & & 138. & & 138. & & 138. & & 0.73 \\
\hline $\mathrm{ck}($ mean $\pm \mathrm{SD})$ & & 3.74 & & 3.81 & & 3.77 & & 0.71 \\
\hline ANA (median [I & & 52.0 & & 81.8 & 33.0] & 70.8 & $9.0]$ & 0.29 \\
\hline Anti.ds.DNA (me & dian [IQR]) & 31.6 & & 79.0 & $10.0]$ & 38.0 & 61.8] & 0.1 \\
\hline C3 (median [IQF & & 76.0 & 3.0] & 77.0 & 8.0] & 76.5 & 5.0] & 0.76 \\
\hline C4 (median [IQ & & 11.0 & & 12.0 & & 12.0 & & 0.48 \\
\hline SLEDAI_2K.Scor & (median [IQR]) & 20.0 & $9.0]$ & 43.0 & 5.0] & 28.5 & 8.0] & $0.001 *$ \\
\hline Biopsy class & Non & 0 & $0.0 \%$ & 0 & $0.0 \%$ & 0 & $0.0 \%$ & \\
\hline & Class 1 & 0 & $0.0 \%$ & 0 & $0.0 \%$ & 0 & $0.0 \%$ & \\
\hline & Class 2 & 0 & $0.0 \%$ & 1 & $5.3 \%$ & 1 & $5.3 \%$ & \\
\hline & Class 3 & 0 & $0.0 \%$ & 2 & $10.5 \%$ & 2 & $10.5 \%$ & \\
\hline & Class 4 & 0 & $0.0 \%$ & 12 & $63.2 \%$ & 12 & $63.2 \%$ & \\
\hline & Class 5 & 0 & $0.0 \%$ & 3 & $15.8 \%$ & 3 & $15.8 \%$ & \\
\hline & Class 4-5 & 0 & $0.0 \%$ & 0 & $0.0 \%$ & 0 & $0.0 \%$ & \\
\hline & Class 6 & 0 & $0.0 \%$ & 1 & $5.3 \%$ & 1 & $5.3 \%$ & \\
\hline Biopsy.Al (medi & ? [IQR]) & . & & 5.5 & & - & & \\
\hline Biopsy.Cl (medi & ( [IQR]) & . & & 3.5 & & - & & \\
\hline
\end{tabular}

Data are expressed as frequency $(N, \%)$, mean $\pm S D$, and median (IQR). Test used: Fisher exact or Monte-Carlo for data expressed as frequency, Mann-Whitney $U$ test for data expressed as median (IQR), and Student's $t$ test for data expressed as mean \pm SD 
Table 3 Correlation between GAS5, MALAT1, and clinical and laboratory variables

\begin{tabular}{|c|c|c|c|c|c|c|c|c|}
\hline \multirow[t]{3}{*}{ Variable } & \multicolumn{4}{|c|}{ Non-nephritis } & \multicolumn{4}{|c|}{ Nephritis } \\
\hline & \multicolumn{2}{|c|}{$\begin{array}{l}\text { Relative expression of } \\
\text { GAS5 }\end{array}$} & \multicolumn{2}{|c|}{$\begin{array}{l}\text { Relative expression of MALA } \\
\text { T1 }\end{array}$} & \multicolumn{2}{|c|}{$\begin{array}{l}\text { Relative expression of } \\
\text { GAS5 }\end{array}$} & \multicolumn{2}{|c|}{$\begin{array}{l}\text { Relative expression of MALA } \\
\text { T1 }\end{array}$} \\
\hline & $r$ & $p$ & $r$ & $p$ & $r$ & $p$ & $r$ & $p$ \\
\hline Age & -0.052 & 0.824 & -0.327 & 0.148 & -0.277 & 0.252 & -0.002 & 0.994 \\
\hline Marital status & 0.412 & 0.064 & -0.023 & 0.921 & -0.138 & 0.572 & -0.23 & 0.344 \\
\hline Blood pressure & -.562 & $0.008^{*}$ & -0.214 & 0.352 & -0.078 & 0.751 & 0 & 1 \\
\hline $\mathrm{Hb}$ & 0.064 & 0.782 & 0.3 & 0.186 & -0.213 & 0.382 & -0.079 & 0.748 \\
\hline $\mathrm{RBC}$ & 0.174 & 0.45 & 0.278 & 0.222 & -0.02 & 0.935 & -0.056 & 0.819 \\
\hline WBC & 0.351 & 0.119 & 0.169 & 0.463 & 0.26 & 0.282 & -0.067 & 0.786 \\
\hline Lymphocytes & 0.418 & 0.059 & 0.051 & 0.827 & 0.172 & 0.482 & -0.074 & 0.764 \\
\hline PLT & -0.146 & 0.529 & 0.041 & 0.859 & -0.04 & 0.871 & 0.056 & 0.819 \\
\hline S. creatinine & -0.152 & 0.511 & 0.026 & 0.912 & 0.244 & 0.314 & 0.353 & 0.138 \\
\hline Can & 0.039 & 0.868 & 0.151 & 0.514 & 0.12 & 0.625 & 0.105 & 0.67 \\
\hline $\mathrm{Ck}$ & 0.12 & 0.605 & 0.225 & 0.326 & 0.196 & 0.421 & 0.052 & 0.833 \\
\hline ANA & 0.014 & 0.953 & -0.017 & 0.941 & -0.021 & 0.932 & 0.009 & 0.972 \\
\hline Anti.ds.DNA & 0.023 & 0.92 & 0.116 & 0.616 & 0.127 & 0.603 & 0.128 & 0.601 \\
\hline C3 & 0.126 & 0.586 & 0.261 & 0.253 & -0.069 & 0.778 & 0.258 & 0.286 \\
\hline $\mathrm{C} 4$ & 0.268 & 0.24 & 0.405 & 0.068 & -0.001 & 0.997 & 0.256 & 0.289 \\
\hline UOP & -0.288 & 0.205 & -0.188 & 0.414 & 0.321 & 0.18 & 0.045 & 0.853 \\
\hline SLEDAI_2K.Score & 0.456 & $0.038^{*}$ & 0.093 & 0.687 & -0.216 & 0.375 & -0.137 & 0.576 \\
\hline
\end{tabular}

$r$ Spearman correlation coefficient, $p p$ value

${ }^{*} r$ is significant at $p<0.05$

proteinuria $(p<0.001)$ and serum creatinine $(p=0.004)$, and casts present in the urine $(p<0.001)$, and SLEDAI score $(p=0.001)$ (Table 2).

There was no correlation among lncRNA (GAS5 and MALAT1) expression, activity markers, including anti-dsDNA titers, complement level c3 and c4, and other hematological parameters. In addition, SLEDAI score was not correlated to MALAT1 relative expression, but it was positively correlated to GAS5 relative expression in the NN subgroup (Table 3).

GAS5 expression was significantly correlated to glomerulosclerosis $(p=0.044)$, interstitial fibrosis (0.028), and tubular atrophy degree $(p=0.031)$. This might be attributed to GAS5 association with chronicity pathological markers in LN patients. On the other hand, it showed no significant correlation with

Table 4 Correlation between GAS5, MALAT1, and histopathological markers of activity and chronicity

\begin{tabular}{|c|c|c|c|c|}
\hline \multirow[t]{2}{*}{ Variable } & \multicolumn{2}{|c|}{ Relative expression of GAS5 } & \multicolumn{2}{|c|}{ Relative expression of MALAT1 } \\
\hline & $r$ & $p$ value & $r$ & $p$ value \\
\hline Endocapillary hypercellularity percentage & .218 & .604 & -.289 & .487 \\
\hline Hyaline lesions & .184 & .636 & -.244 & .527 \\
\hline Cellular crescents & -.105 & .773 & -.276 & .440 \\
\hline Fibrinoid necrosis & -.501 & .116 & .300 & .370 \\
\hline Karyorrhexis & .256 & .475 & -.294 & .409 \\
\hline Interstitial infiltration & .071 & .809 & .322 & .261 \\
\hline Sclerotic glomeruli & $.615^{*}$ & .044 & -.080 & .816 \\
\hline Fibrous crescents & .413 & .270 & -.411 & .272 \\
\hline Atrophic tubules & $.647^{*}$ & .031 & .077 & .821 \\
\hline Interstitial fibrosis & $.565^{*}$ & .028 & -.047 & .869 \\
\hline
\end{tabular}

$r$ Spearman correlation coefficient, $p p$ value

${ }^{*} r$ is significant at $p<0.05$ 


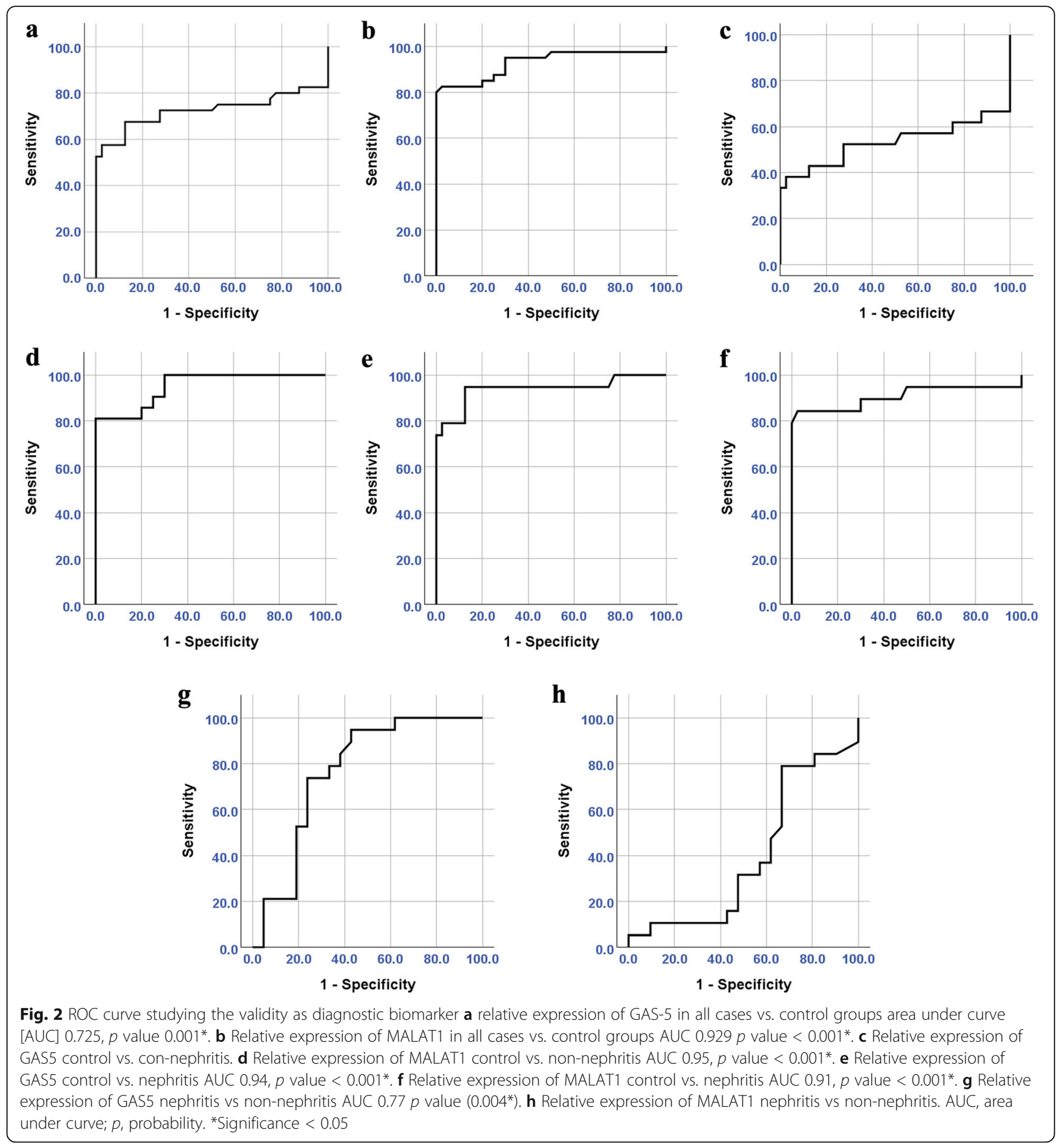

any of the renal histopathological activity parameters, including endocapillary hypercellularity, cellular crescents, fibrinoid necrosis, karyorrhexis, and active interstitial infiltration (Table 4).

Receiver operating characteristic (ROC) curve analysis was performed to discriminate SLE patients from healthy controls using MALAT1 and GAS5 gene expression as discrimination marker (Fig. 2).

\section{Discussion}

In this study, we investigated lncRNA expression (MALAT1 and GAS5) in SLE patients with/without nephritis. We found that the lncRNA (MALAT1) was aberrantly expressed in comparison with healthy controls, while GAS5 expression levels in SLE patients was significantly reduced in comparison with controls. Results suggested that MALAT1 and GAS5 plasma levels could serve as potential biomarkers for SLE. 
Previously, it has been shown that lncRNA (GAS5)which is important for normal growth, apoptosis, and cell cycle function-was consistent with an increased risk of developing SLE in a mouse model [18]. GAS5 was also involved in human SLE development [19]. Previous studies have indicated that GAS5 is significantly lower in SLE patients compared to healthy controls [20,21].

It has been found that MALAT1 expression increases abnormally in SLE patients. Previous studies have proven that MALAT1 was involved in Sirtuin 1 (SIRT1) signaling regulation, which contributes to lupus disease initiation and maintenance [22]. SIRT1 expression was reduced significantly after MALAT1 knockdown, which suggested its main regulatory function in SLE pathogenesis $[23,24]$. The role of other IncRNAs (NEAT2, CTC$471 \mathrm{~J} 1.2$, and lnc-DC) was investigated in LN patients in previous reports [25]. To investigate whether GAS5 and MALAT1 expression is related to renal affection in SLE, we contrasted their relative expression levels in SLE patients with/without nephritis. Our findings showed that GAS5 relative expression in LN patients is significantly downregulated compared to patients with NN. This indicates that GAS5 could be used as a biomarker to distinguish the SLE with/without LN.

GAS5 relative expression was significantly associated with the degree of glomerulosclerosis, interstitial fibrosis, and tubular atrophy. This may indicate an association between the dysregulated IncRNA [GAS5] and poor renal outcomes.

By further investigations on the correlation of lncRNA (GAS5, MALAT1) with SLEDAI-2 K score between LN and NN, a positive correlation was found between GAS5 and SLEDAI-2 K score in the NN subgroup, not in the LN subgroup. Currently, there is no study exploring GAS5 association and lupus activity in differentiating between patients with/without nephritis. This observation needs to be further studied to clarify this point.

IncRNA (GAS5) was negatively correlated to blood pressure in $\mathrm{NN}$ group, which denotes the higher risk of hypertension in SLE patients with downregulated GAS5. This can be explained by the previous observation of GAS5 inhibitory effect on the proliferation and migration of vascular smooth muscle cells, for which it can serve as a potential hypertension therapeutic target [26]. Considering GAS5 as a potential biomarker for hypertension has been previously elucidated in animal models [27].

This research may have many limitations. First is examining patients from only one hospital, which may limit finding generalization. Second, potential confounding factors such as different treatment strategies among patients should be considered in data interpretation. To reveal the exact further function of these IncRNAs in SLE and further evaluate their diagnostic and prognostic efficacy in lupus nephritis, future studies must be conducted.

\section{Conclusion}

The lncRNA (GAS5 and MALAT1) may serve as diagnostic biomarkers for SLE. Moreover, GAS5 may distinguish SLE LN patients from NN patients and may predict renal fibrosis in $\mathrm{LN}$ patients.

\section{Abbreviations \\ GAS5: Growth arrest-specific 5; LncRNA: Long non-coding RNA; MALA T1: Metastasis-associated lung adenocarcinoma transcript 1; PBMCs: Peripheral blood mononuclear cells; SLE: Systemic lupus erythematosus; LN: Lupus nephritis; NN: Lupus non-nephritis; SLEDAI: Systemic lupus erythematosus disease activity index; Anti- dsDNA: Anti-double stranded DNA; GAPDH: Glyceraldehyde 3-phosphate dehydrogenase}

\section{Acknowledgements}

Not applicable.

\section{Authors' contributions}

ME, NM amd ME designed the research and performed the experiments. RS and $A E$ recruited the patients and processed the samples. All authors analyzed the data, shared in writing the manuscript, and read and approved the final version of this manuscript.

Funding

No funding was received.

Availability of data and materials

The datasets used and analyzed during the current study are available from the corresponding author on reasonable request.

Ethics approval and consent to participate

This study was approved by the Institutional Review Board of Mansoura Faculty of Medicine with approval number [R. 20.01.731]. Informed written consent was obtained from all individuals included in this study.

Consent for publication

Not applicable.

\section{Competing interests}

The authors declare that they have no competing interests.

\section{Author details}

${ }^{1}$ Medical Biochemistry Department, Faculty of Medicine, Mansoura University, Mansoura, Egypt. ${ }^{2}$ Nephrology Department, Nephrology and Dialysis Unit, Faculty of Medicine, Mansoura University, Mansoura, Egypt. ${ }^{3}$ Rheumatology and Rehabilitation Department, Faculty of Medicine, Mansoura University, Mansoura, Egypt.

Received: 24 August 2020 Accepted: 17 November 2020

Published online: 11 January 2021

References

1. Rahman A, Isenberg DA (2008) Mechanisms of disease. Systemic lupus erythematosus. N Engl J Med 358:929-939

2. Wang L-K, Chen X-F, He D-D, Li Y, Fu J (2017) Dissection of functional IncRNAs in Alzheimer's disease by construction and analysis of IncRNAmRNA networks based on competitive endogenous RNAs. Biochem Biophys Res Commun 485(3):569-576

3. Wu Y, Zhang F, Ma J, Zhang X, Wu L, Qu B et al (2015) Association of large intergenic noncoding RNA expression with disease activity and organ damage in systemic lupus erythematosus. Arthritis Res Ther 17(1):131

4. Gibb EA, Brown CJ, Lam WL (2011) The functional role of long non-coding RNA in human carcinomas. Mol Cancer 10(1):38 
5. Sigdel KR, Cheng A, Wang Y, Duan L, Zhang Y (2015) The emerging functions of long noncoding RNA in immune cells: autoimmune diseases. J Immunol Res 848790

6. Ma X-Y, Wang J-H, Wang J-L, Ma CX, Wang X-C, Liu F-S (2015) Malat1 as an evolutionarily conserved IncRNA, plays a positive role in regulating proliferation and maintaining undifferentiated status of early-stage hematopoietic cells. BMC Genomics 16(1):676

7. Ji P, Diederichs S, Wang W, Böing S, Metzger R, Schneider PM et al (2003) MALAT-1, a novel noncoding RNA, and thymosin $\beta 4$ predict metastasis and survival in early-stage non-small cell lung cancer. Oncogene. 22(39):80318041

8. Michalik KM, You X, Manavski Y, Doddaballapur A, Zörnig M, Braun T et al (2014) Long noncoding RNA MALAT1 regulates endothelial cell function and vessel growth. Circ Res 114(9):1389-1397

9. Watts R, Johnsen VL, Shearer J, Hittel DS (2013) Myostatin-induced inhibition of the long noncoding RNA Malat1 is associated with decreased myogenesis. Am J Physiol-Cell Physiol 304(10):C995-C1001

10. Suo QF, Sheng J, Qiang FY, Tang ZS, Yang YY (2018) Association of long non-coding RNA GAS5 and miR-21 levels in CD4+ T cells with clinical features of systemic lupus erythematosus. Exp Ther Med 15(1):345-350

11. Teruel M, Alarcón-Riquelme ME (2016) The genetic basis of systemic lupus erythematosus: what are the risk factors and what have we learned. J Autoimmun 74:161-175

12. Atianand MK, Hu W, Satpathy AT, Shen Y, Ricci EP, Alvarez-Dominguez JR et al (2016) A long noncoding RNA lincRNA-EPS acts as a transcriptional brake to restrain inflammation. Cell. 165(7):1672-1685

13. Wu G-C, Hu Y, Guan S-Y, Ye D-Q, Pan H-F (2019) Differential plasma expression profiles of long non-coding RNAs reveal potential biomarkers for systemic lupus erythematosus. Biomolecules 9(6):206

14. Tansey E, Lupus S, Gladman D, Esdaile J, Urowitz M (1999) Guidelines for referral and management of systemic lupus erythematosus in adults. Arthritis Rheum. American College of Rheumatology Ad Hoc Committee on Systemic Lupus Erythematosus Guidelines

15. Petri M, Orbai AM, Alarcón GS, Gordon C, Merrill JT, Fortin PR et al (2012) Derivation and validation of the Systemic Lupus International Collaborating Clinics classification criteria for systemic lupus erythematosus. Arthritis Rheum 64(8):2677-2686

16. Gladman DD, Ibañez D, Urowitz MB (2002) Systemic lupus erythematosus disease activity index 2000. J Rheumatol 29(2):288-291

17. Schmittgen TD, Livak KJ (2008) Analyzing real-time PCR data by the comparative CT method. Nat Protoc 3(6):1101

18. Haywood M, Rose S, Horswell S, Lees M, Fu G, Walport M et al (2006) Overlapping BXSB congenic intervals, in combination with microarray gene expression, reveal novel lupus candidate genes. Genes Immun 7(3):250-263

19. Suarez-Gestal M, Calaza M, Endreffy E, Pullmann R, Ordi-Ros J, Sebastiani GD et al (2009) Replication of recently identified systemic lupus erythematosus genetic associations: a case-control study. Arthritis Res Ther 11(3):R69

20. Wu G-C, Li J, Leng R-X, Li X-P, Li X-M, Wang D-G et al (2017) Identification of long non-coding RNAs GAS5, linc0597 and Inc-DC in plasma as novel biomarkers for systemic lupus erythematosus. Oncotarget 8(14):23650

21. Mayama T, Marr A, Kino T (2016) Differential expression of glucocorticoid receptor noncoding RNA repressor Gas5 in autoimmune and inflammatory diseases. Horm Metab Res 48(08):550-557

22. Li Z, Chao T-C, Chang K-Y, Lin N, Patil VS, Shimizu C et al (2014) The long noncoding RNA THRIL regulates TNFa expression through its interaction with hnRNPL. Proc Natl Acad Sci 111(3):1002-1007

23. Yang $H$, Liang $N$, Wang $M$, Fei $Y$, Sun J, Li Z et al (2017) Long noncoding RNA MALAT-1 is a novel inflammatory regulator in human systemic lupus erythematosus. Oncotarget 8(44):77400

24. Zhao C-N, Mao Y-M, Liu L-N, Li X-M, Wang D-G, Pan H-F (2018) Emerging role of IncRNAs in systemic lupus erythematosus. Biomed Pharmacother 106:584-592

25. Saleh AA, Kasem HE, Zahran E, El-Hefnawy SM (2020) Dysregulation of cellfree long non-coding RNAs [NEAT2, CTC-471 J1.2 and Inc-DC] in Egyptian systemic lupus and lupus nephritis patients. Meta Gene 24:100665

26. Liu K, Liu C, Zhang Z (2019) IncRNA GAS5 acts as a ceRNA for miR-21 in suppressing PDGF-bb-induced proliferation and migration in vascular smooth muscle cells. J Cell Biochem 120(9):15233-15240

27. Wu Y, Zhang Z, Ren S, Li K, Ning Q, Jiang X (2019) Aberrant expression of long noncoding RNAs in the serum and myocardium of spontaneous hypertensive rats. Mol Biol Rep 46(6):6399-6404

\section{Publisher's Note}

Springer Nature remains neutral with regard to jurisdictional claims in published maps and institutional affiliations.

\section{Submit your manuscript to a SpringerOpen ${ }^{\circ}$ journal and benefit from:}

- Convenient online submission

- Rigorous peer review

- Open access: articles freely available online

- High visibility within the field

- Retaining the copyright to your article

Submit your next manuscript at $\boldsymbol{\nabla}$ springeropen.com 